Journal of Zhejiang University-SCIENCE B (Biomedicine \& Biotechnology) ISSN 1673-1581 (Print); ISSN 1862-1783 (Online)

www.zju.edu.cn/jzus; www.springerlink.com

E-mail: jzus@zju.edu.cn

\title{
Correspondence:
}

\section{Transcatheter aortic valve implantation for Chinese patients with bicuspid aortic valve}

\author{
Yu-guo WENG \\ (Deutsches Herzzentrum Berlin, Augustenburger Platz 1, 13353 Berlin, \\ Germany) \\ E-mail: weng@dhzb.de
}

doi:10.1631/jzus.B1500063

The recent paper by the corresponding author Jian-an WANG and his team entitled "Evaluation of the safety and efficacy of transcatheter aortic valve implantation in patients with a severe stenotic bicuspid aortic valve in a Chinese population" (Liu et al., 2015), published in the Journal of Zhejiang UniversitySCIENCE B (Biomedicine \& Biotechnology), is very impressive. They evaluated the safety and efficacy of transcatheter aortic valve implantation (TAVI) in patients with bicuspid aortic valve (BAV) and tricuspid aortic valve (TAV) for the first time in the Chinese population. This paper reported 40 cases of clinical experience of TAVI, and first explicitly put forward the indication of stenosis in the BAV. The early and mid-term outcomes between BAV and TAV groups are almost the same, and the high procedural success rate and low complication rate of their study are encouraging.

However, they found that the diameter of the ascending aorta in the BAV group $((40.4 \pm 4.4) \mathrm{mm})$ is larger than that in the TAV group. As we know, the BAV is often associated with ascending aortic dilatation that might be the result of hemodynamic changes and genetic backgrounds (Loscalzo et al., 2007). Replacement of the ascending aorta is indicated in patients with a BAV who are undergoing surgical aortic valve replacement (SAVR) if the diameter of the ascending aortic is $>45 \mathrm{~mm}$ (Erbel et al., 2014). In

(D) ORCID: Yu-guo WENG, http://orcid.org/0000-0002-9970-9479 (c) Zhejiang University and Springer-Verlag Berlin Heidelberg 2015 their study, patients with ascending aortic diameter $>50 \mathrm{~mm}$ were excluded, but two patients with dilated ascending aorta (48.4 and $49.4 \mathrm{~mm}$, respectively) who were evaluated as surgical high risk (advanced age and poor heart function, etc.) underwent TAVI. However, there is still no clear evidence about the remodeling of ascending aorta and long-term outcomes of BAV patients with dilated ascending aorta after TAVI treatment. Follow-up research of the diameter of the ascending aorta and survival in these patients will be necessary and also very interesting.

BAV is still deemed as a relative contraindication for TAVI (Vahanian et al., 2012), while the corresponding author Jian-an WANG and his team noted that patients with a severely stenotic BAV can be safely and effectively treated by TAVI (Liu et al., 2015). Meanwhile, $37.5 \%$ of the patients with BAV in their study were much higher than previous reports in Europe (3.0\% to $9.2 \%$ ) (Hayashida et al., 2013; Bauer et al., 2014). Therefore, evaluation of the safety and efficacy of TAVI in patients with a severe stenotic BAV in the Chinese population is valuable for clinical practice and clinical trials to expand the indication for TAVI.

Compared with TAV patients, SAVR is generally performed at a younger age and lower surgical risk among BAV patients (Michelena et al., 2008; Lange et al., 2012). The clinical trials of TAVI in the lower surgical risk and younger patients are ongoing, which might expand the indication for TAVI. Accordingly, this study should contribute to the application of TAVI in more patients with aortic stenosis in the future.

\section{References}

Bauer, T., Linke, A., Sievert, H., et al., 2014. Comparison of the effectiveness of transcatheter aortic valve implantation in patients with stenotic bicuspid versus tricuspid 
aortic valves (from the German TAVI Registry). Am. $J$. Cardiol., 113(3):518-521. [doi:10.1016/j.amjcard.2013. $10.023]$

Erbel, R., Aboyans, V., Boileau, C., et al., 2014. 2014 ESC Guidelines on the diagnosis and treatment of aortic diseases: document covering acute and chronic aortic diseases of the thoracic and abdominal aorta of the adult. The Task Force for the Diagnosis and Treatment of Aortic Diseases of the European Society of Cardiology (ESC). Eur. Heart J., 35(41):2873-2926. [doi:10.1093/eurheartj/ ehu281]

Hayashida, K., Bouvier, E., Lefèvre, T., et al., 2013. Transcatheter aortic valve implantation for patients with severe bicuspid aortic valve stenosis. Circ. Cardiovasc. Interv., 6(3):284-291. [doi:10.1161/CIRCINTERVENTIONS. 112.000084]

Lange, R., Bleiziffer, S., Mazzitelli, D., et al., 2012. Improvements in transcatheter aortic valve implantation outcomes in lower surgical risk patients: a glimpse into the future. J. Am. Coll. Cardiol., 59(3):280-287. [doi:10. 1016/j.jacc.2011.10.868]
Liu, X.B., Jiang, J.B., Zhou, Q.J., et al., 2015. Evaluation of the safety and efficacy of transcatheter aortic valve implantation in patients with a severe stenotic bicuspid aortic valve in a Chinese population. J. Zhejiang Univ.-Sci. B (Biomed. \& Biotechnol.), 16(3):208-214. [doi:10.1631/ jzus.B1500017]

Loscalzo, M.L., Goh, D.L., Loeys, B., et al., 2007. Familial thoracic aortic dilation and bicommissural aortic valve: a prospective analysis of natural history and inheritance. Am. J. Med. Genet. A, 143A(17):1960-1967. [doi:10. 1002/ajmg.a.31872]

Michelena, H.I., Desjardins, V.A., Avierinos, J.F., et al., 2008. Natural history of asymptomatic patients with normally functioning or minimally dysfunctional bicuspid aortic valve in the community. Circulation, 117(21):2776-2784. [doi:10.1161/CIRCULATIONAHA.107.740878]

Vahanian, A., Alfieri, O., Andreotti, F., et al., 2012. Guidelines on the management of valvular heart disease (version 2012): the Joint Task Force on the Management of Valvular Heart Disease of the European Society of Cardiology (ESC) and the European Association for CardioThoracic Surgery (EACTS). Eur. Heart J., 33(19): 2451-2496. [doi:10.1093/eurheartj/ehs109] 